\title{
PSYCHOSOCIAL STRESS AND QUALITY OF LIFE IN PREGNANT ADOLESCENTS
}

\author{
Alejandro Loya-Jimenez, Godeleva R. Ortiz-Viveros, Armando J. Martínez \\ University of Veracruz, Veracruz, México \\ E-mail: psi.cli.alejandro@live.com.mx, roortiz@uv.mx \\ Gabriel Gutiérrez-Ospina \\ National Autonomous University of Mexico, Mexico \\ E-mail: gabo@biomedicas.unam.mx \\ Tania Romo-González \\ University of Veracruz, Veracruz, México \\ E-mail: tromogonzalez@uv.mx
}

\begin{abstract}
In México, perinatal maternal mortality constitutes the tenth cause of death among women between 15 and 29 years of age. Even though the factors that increase the risk of death of young Mexican pregnant women are unclear, it is possible that the psychosocial stress imposed upon them could impair their life's quality in such a profound way that pulls their organisms into a cataclysmic event. To begin exploring the merits of this presumption, we conducted a study aimed at evaluating whether psychosocial stress impacts negatively on the adolescent pregnant women's perception of their quality of life, and thus on their health. One hundred and twenty two pregnant women between 14 and 35 years of age were asked to fill out three questionnaires designed to gather information on background factors, stress symptoms and the perception of their quality of life and health. These data were cross-correlated by using a Pearson correlation analysis. Even though the perceived stress and the estimated quality of life were similar between adolescent and non-adolescent pregnant women, the former were more concerned about their restrictions to have free time and to have readily access to medical attention than the latter. Non-adolescent pregnant women had significantly greater emotional support from their families. Also, there was a relationship between the stress symptoms and the quality of life perception in pregnancy and this relationship varies in adolescent and non-adolescents. These results mean that nonetheless the level of stress symptoms do not vary with the pregnancy age; it has a different kind of impact on the quality of life perception, which may be used in the development of targeted interventions.
\end{abstract}

Key words: stress symptoms, quality of life perception, coping strategies, pregnancy interventions.

\section{Introduction}

Reducing high mortality rates among adolescent pregnant women constitutes one of the main challenges faced by the Mexican public health services at the beginning of the new millennium (Auchter, Galeano, \& Zacarías, 2004; INEGI, 2011b). One way used by the medical federal authori- 
ties to tackle this problem was to devise strategies aim at discouraging pregnancy among adolescent women. Unfortunately, the educational campaigns launched by the government to reach this goal have been so far ineffective; the percentage of adolescent pregnancies has remained unchanged for the past 8 years (INEGI, 2010). As a society, we are forced to compliment educational programs with effective medical measures that could help decreasing the number of adolescent mother dying from pregnancy-associated complications. The identification of factors that predispose adolescent pregnant women to develop fatal conditions is then a priority.

Pregnancy and perinatal pathologies have a multifactorial substrate (Ruiz, Fullerton, \& Dudley, 2003). Nonetheless authors generally coincide in considering the stress as the single fundamental factor underlying most of these pathologies. In a conservative society, adolescent pregnant women may develop psychological stress after being neglected by their families, abandoned by their partners, marked by social prejudice and/or subjected to financial burden (Marrero, Aguilera, \& Aldrete, 2008; Muñoz \& Oliva, 2009; Paarlberg, Vingerhoets, Passchier, Dekker, \& Van Geijn, 1995). Such stressors may lead to premature births, fetal malnutrition, intrauterine growth retardation and, specifically in adolescents, the development of pre-eclampsia, eclampsia, abortion (whether spontaneous or induced) and even to suicidal attempts (Bhattacharya, Davies, Meredith, \& Preston, 2011; Muñoz \& Oliva, 2009). Prenatal and perinatal psychological stress not only affects the adolescent pregnant women's health through altering physiological parameters, it might also influence their perception on their quality of life by modifying their feeling of well-being, satisfaction with motherhood and perception of independence among other parameters (Guarino, Scremin, \& Borrás, 2010).

In spite of this possibility, until now, it is not known whether the level of psychosocial stress indeed modifies the perception of the quality of life, especially in pregnant adolescents. Thus, in this work we evaluated this possibility.

\section{Methodology of Research}

\section{Cohorts and Sample Size}

A group of adolescent (age range 15-19 years old; $n=60$ ) and another of non-adolescent (age range 20-35; $n=64$ ) pregnant women were constituted based on the consecutive cases' nonprobabilistic sampling method (Miján de la Torre, 2002). All women attended, between December 2012 to March 2013, either of three different medical centers located all at the city of Xalapa, Veracruz, México and have access to equivalent quality of medical care. All participants signed the informed consent form. Our sample excluded from the onset illiterate women or those with abortion risks and mental illness. The socio-demographical variables featured by both women groups are presented in Table 1. No statistically significant differences were observed when sociodemographic variables were compared between groups.

Table 1. Socio-demographic variables.

\begin{tabular}{ccc}
\hline & $\begin{array}{c}\text { Adolescent } \\
(\%)\end{array}$ & $\begin{array}{c}\text { Non Adolescent } \\
(\%)\end{array}$ \\
\hline Trimester of pregnancy & & \\
\hline First & 13.3 & 14.1 \\
Second & 55 & 57.8 \\
Third & 31.7 & 28.1 \\
\hline Total & 100 & 100 \\
\hline Marital status & & \\
\hline Single & 15 & 9.4
\end{tabular}


Adolescent

$(\%)$

Non Adolescent

(\%)

\begin{tabular}{ccc}
\hline Married & 31.7 & 21.9 \\
Free union & 50 & 48.4 \\
Separated & 3.3 & 18.8 \\
Did not respond & - & 1.6 \\
\hline Total & 100 & 100 \\
\hline Schooling & & \\
\hline Primary school & 26.7 & 17.2 \\
Secundary school & 31.7 & 31.3 \\
High school & 28.3 & 25 \\
College & 5 & 25 \\
Did not respond & 8.3 & - \\
Literate & - & 1.6 \\
\hline Total & 100 & 100 \\
\hline
\end{tabular}

Living with their couple

\begin{tabular}{ccc}
\hline No & 18.3 & 15.6 \\
Yes & 81.7 & 84.4 \\
\hline Total & 100 & 100 \\
\hline Labour & & \\
\hline No & 88.3 & 81.3 \\
Yes & 3.3 & 17.2 \\
Did not respond & 8.3 & 1.6 \\
\hline Total & 100 & 100 \\
\hline
\end{tabular}

Maternity leave

$\begin{array}{lll}\text { No } & 90 & 93.3\end{array}$

Did not respond $\quad 8.3$

Total $100 \quad 100$

Family income

\begin{tabular}{ccc}
\hline Insuffiecient & 36.7 & 40.6 \\
Sufficient & 48.3 & 59.4 \\
Did not respond & 15 & - \\
Total & 100 & 100 \\
\hline Do not work or study & & \\
\hline No & 37 & 87.5 \\
Yes & 63 & 12.5 \\
\hline Total & 100 & 100 \\
\hline
\end{tabular}




\section{Psychological Metric}

The level of stress, the quality of life perception and the pregnancy data were estimated through the following instruments:

1. General Questionnaire (Senties-Amezcua \& Ortiz-Viveros, 1993). This instrument consisted of 46 questions divided into 7 sections designed to obtain information on the socioeconomic and health status, family and the couple issues, emotional condition, attitudes toward pregnancy, attitudes toward birth, information about pregnancy and childbirth and social support networks. The response variables in this section were analyzed with Student $t$ test for independent samples; the assumptions of normality and the homogeneity of variances were verified.

2. Stress Symptoms Inventory (for its acronym in Spanish ISE). ISE was used to estimate the frequency of stress manifestations during daily life in both populations of pregnant women. ISE consists of 30 items that have four response options that assess the perceived frequency of psychic, physical and/or social stress related symptoms based on a scale that goes from "never" ( 0 points) to "always (4 points) (Benavides et al., 2002). Each symptom category has different threshold values so that the participant can qualify the relative level of discomfort (low, moderate or high) experienced. This instrument has factorial and convergent validities, as well as psychometric consistency (Benavides, Moreno, Barrosa, \& González, 2002). The response variables were analyzed through the use of Generalized Linear Models (GLM) with a two-factor design, where one factor corresponded to the non adolescent or adolescent condition and the second factor was the trimester of gestation.

3. Quality of life and health Inventory (for its acronym in Spanish InCaViSa). This instrument explores the Concerns, Physical performance, Isolation, Body perception, Cognitive functions, Attitude to the treatment, Free time, Everyday life, Family, Social networks, Medical dependence, Relationship with the doctor (Riveros, Sanchez-Sosa, \& Del Águila, 2010). Each category is evaluated based on a scale that goes from "never" (0 points) to "always (5 points). InCaViSa's psychometric properties have internal consistency, concurrent validity and enough sensitivity to distinguish between different health conditions (Riveros, Sanchez-Sosa, \& Del Águila, 2010). For this study purpose, we switched the word "disease" by "pregnancy". The response variables were analyzed through the use of Generalized Linear Models (GLM) with a two-factor design, where one factor corresponded to the non adolescent or adolescent condition and the second factor was the trimester of gestation. In addition, Student $t$ tests were for independent samples were to evaluate the scores for each category between groups after verifying the assumptions of variances normality and the homogeneity.

\section{Multivariate Data Analysis}

The relationships among data obtained through the different instruments were plotted and analyzed using a Principal Components (PC) followed by Generalized Linear Models (GLM) with a unifactorial design for inference from multivariate ordination. Also Pearson's correlations tests were carried out to compare the variables associations between groups.

\section{Results of Research}

\section{General Questionnaire}

\section{A) Health status}

Sixty three percent of the participants visited the physician once a month. From this group, ninety nine percent of them followed medical advices; sixty eight percent had scheduled physi- 
cal activity and forty two percent had had previous pregnancies. From the last percentage, $29 \%$ were non-adolescents and $13 \%$ were adolescents $(t=-4.3$, df: $122 ; \mathrm{p}<0.001)$.

\section{B) Couple status}

Seventy four percent of the participants reported no major problems with their couple. From this group, sixty eight percent that experience some disagreements solved them chatting, eighty five percent felt their selves responsible to their partner, and seventy six percent felt very happy with their partner. At the time of knowing the pregnancy, sixty percent of these women felt well and happy, while five percent of them felt bad, sad and afraid. Forty eight of the participants reported the pregnancy to be unplanned and sixty eight percent of the couples expressed to be happy with the news. Furthermore, sixty four percent of women felt that their partners were kindest before they knew about pregnancy, being this comment more frequently expressed by non adolescent women ( $\mathrm{t}=11.5$, df: $122 ; \mathrm{p}<0.001)$.

\section{C) Family status}

With regard to family relationships and bonding, seventy two percent of the pregnant women reported to have no problems with their nuclear family. Pregnant adolescents, however, disclosed to have a higher incidence of family troubles $(t=-5.2$, df: 122; $\mathrm{p}<0.001)$. From women subjected to family distress, sixty percent of them reported to have solved this issue by talking about it. However, non adolescent women appear to have talked more often with their family than in the adolescent ones ( $t=-4.7$, df: 122; $<<0.001$ ). From the sampled population, seventy three percent of pregnant women reported to feel safe and protected by their family. Interestingly, non adolescents reported these perceptions more often $(t=-6.2, d f: 122 ; p<0.001)$.

In relation to the emotional response of the family members to the news of being their daughters pregnant, we found that forty eight percent of the families took the news positively. However, the families of non adolescent pregnant women's expressed these attitudes more frequently $(\mathrm{t}=$ -3.8 , df: $122 ; \mathrm{p}<0.001)$. Also, fifty three percent of non adolescent pregnant women reported to perceive their families warmest the before their pregnancy $(\mathrm{t}=-3.3$, df: 122; $\mathrm{p}<0.001)$.

D) Emotional status in pregnancy

The parameter that worrisome the most pregnant women was the baby's health (74\%). Five percent of the women interviewed expressed depression symptoms. Fifty six of them were adolescents.

E) Information on pregnancy and childbirth

Ninety one percent of the pregnant women in this study received information about pregnancy and childbirth. The attending physicians were the primary source for forty eight percent of them, followed by those (34\%) for whom the mothers and/or sisters provided the information. Surprisingly, twenty three percent of the participants informed to have no knowledge about the circumstances that surround child delivery.

F) Attitudes toward pregnancy and childbirth

None of these variables show significant differences between groups. Forty seven percent of women reported their lives to be greatly influenced by pregnancy. Sixty percent of the participants did not modify their eating habits, fifty six percent never felt afraid to go out alone, sixty percent estimated child delivery as a painful process, forty five percent reported fear to delivery associated pain, eighty nine percent wished to have a vaginal delivery, and eighty nine percent felt fulfilled with their pregnancy and rated it as satisfactory. 
G) Social networks

Most women expressed their partners to be the greatest support during their pregnancies.

Stress Symptoms Inventory

There were no statistically significant differences in any of the categories assessed by the inventory among groups or trimesters. However, all the women reported the physical, psychic, social and global stress symptoms as moderate (Figure 1).
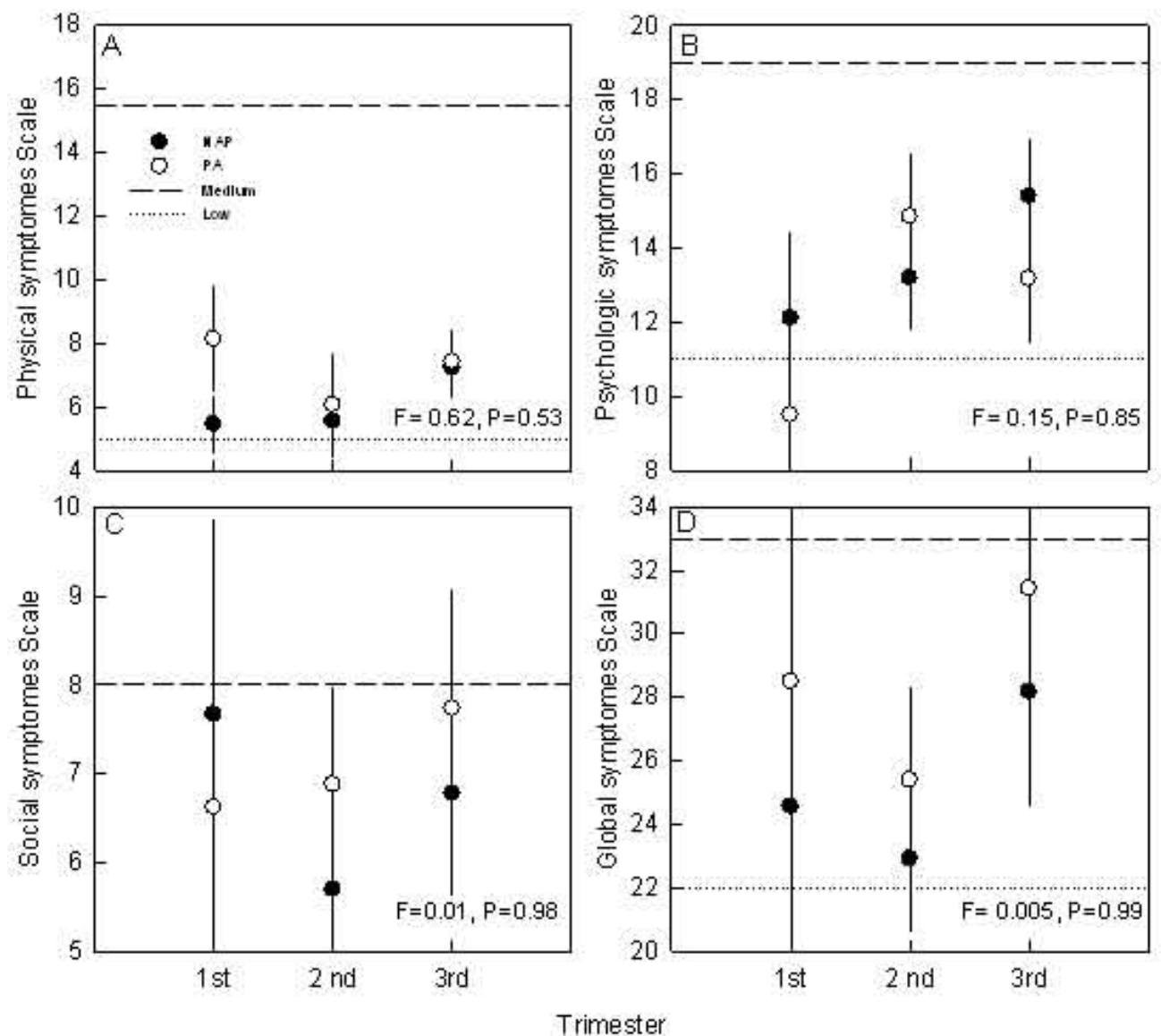

Figure 1: Stress Symptoms Inventory. The graphs correspond to the mean ( $\pm \mathrm{EE}$ ) values of stress symptoms. NA= Non adolescents $(\bullet), \mathrm{A}=$ Adolescents $(0)$. The lines indicate the estimated stress level (low, moderate and high).

\section{Quality of Life and Health Inventory}

In general, life's quality perception was similar in adolescent and non adolescent pregnant women. Nonetheless, adolescent pregnant women consistently perceived a progressive deterioration of their life's quality as pregnancy advances (Figure 2A; for adolescents: $\mathrm{F}=4.2, \mathrm{p}=0.017$; for non adolescents $\mathrm{F}=3.3, \mathrm{p}=0.04$ ). Also, overall adolescent pregnant women showed an increased medical dependence as pregnancy progresses (Figure 2E; for adolescent: $F=4.2 ; p=0,017$; for non adolescent: $\mathrm{F}=3.3 ; \mathrm{p}=0.40$ ). 

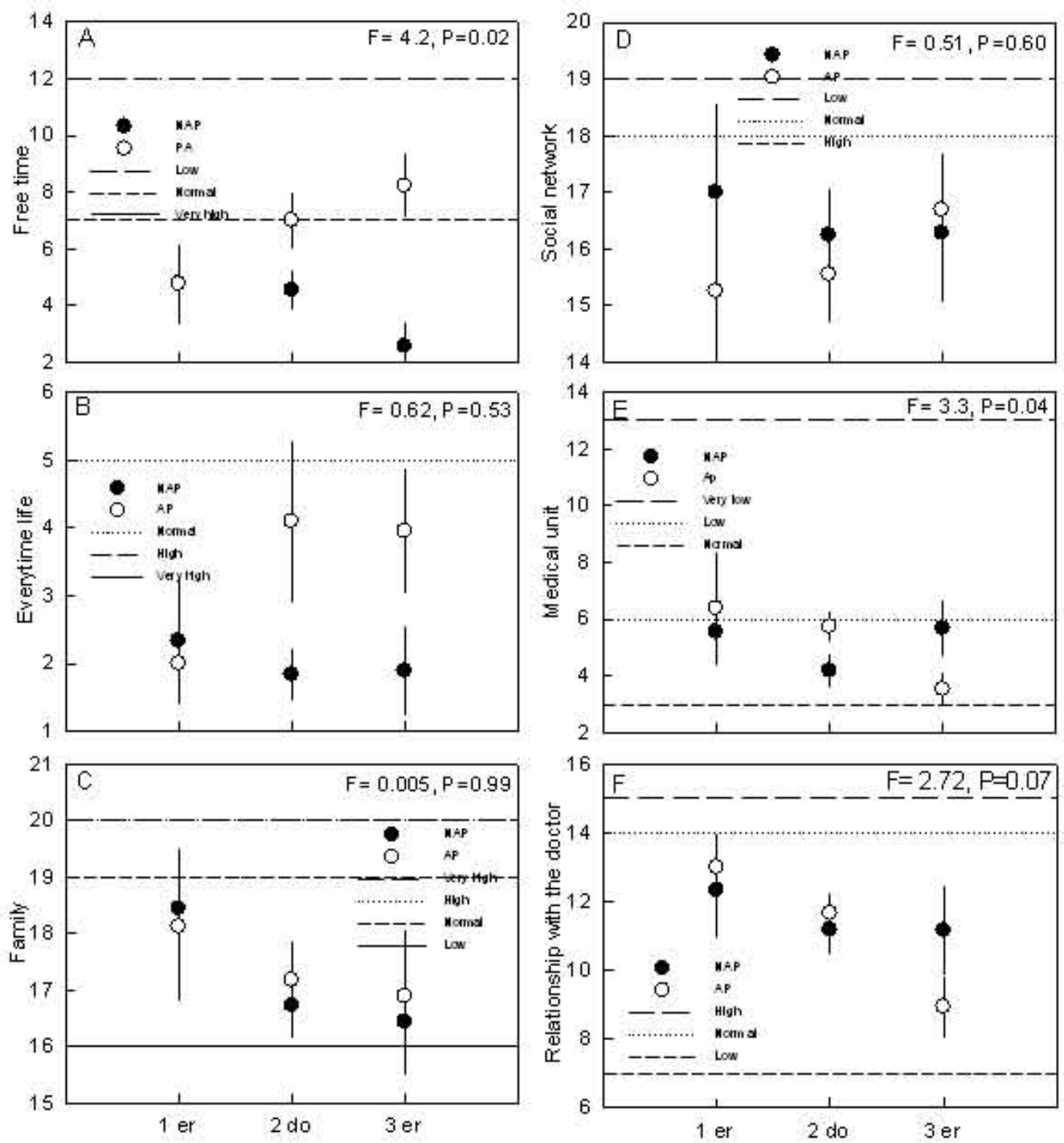

Trimester

Figure 2. Quality of life and health Inventory. Mean ( \pm EE) of Categories of InCaViSa: A) free time, B) everyday life, C) family, D) social networks, E) medical dependence, F) Relationship with the doctor. NA= Non adolescents $(\bullet), A=$ Adolescents $(0)$. The lines indicate the level of the quality of life perception (very low, low, normal, high and very high).

Furthermore, when the time of pregnancy is taken off the statistical analyses, the concerns $(t=2.062, p=0.041)$ and everyday life $(t=2.40, p=0.02)$ categories stand out as significantly different between groups (Figure 3 ). 


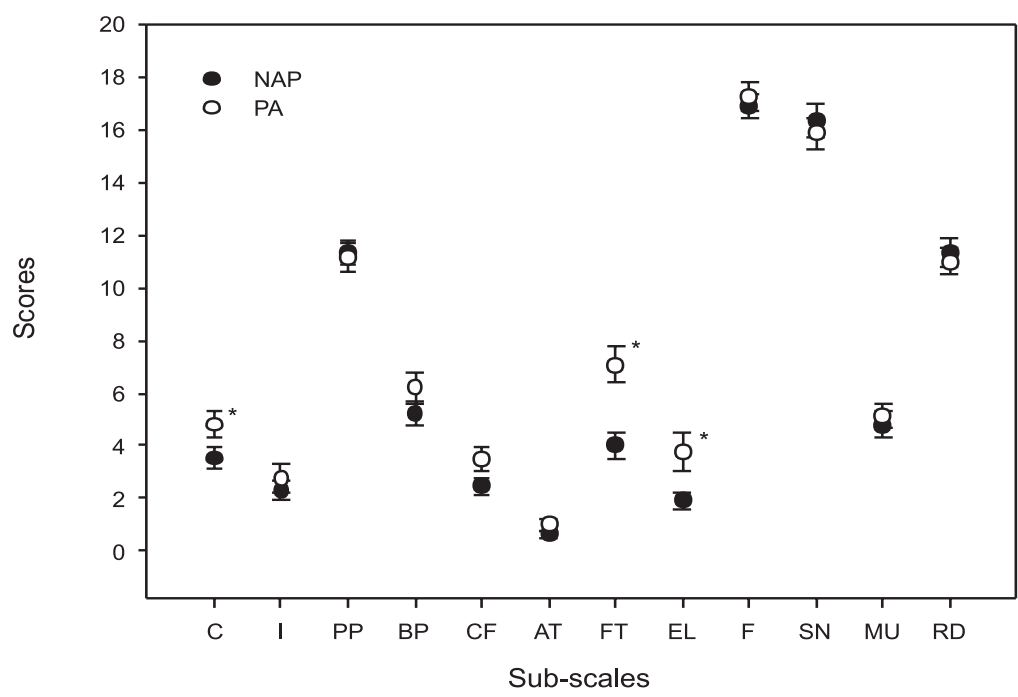

Figure 3. Mean ( \pm EE) of analysis of InCaViSa between adolescents and non adolescents, excluding trimesters. NAP $=$ Non adolescents $(\bullet), \mathrm{PA}=$ Adolescents (o). $C=$ Concerns, $I=$ Isolation, $P P=$ Physical performance, $\mathrm{BC}=$ Body perception, $\mathrm{CF}=$ Cognitive function, $\mathrm{AT}=$ Attitude to the treatment, FT=Free time, EL=Everyday life, F=Family, $S N=$ Social networks, $\mathrm{MD}=$ Medical dependence, $\mathrm{RD}=$ Relationship with the doctor. $* \mathbf{p}<0.05$

\section{Principal Components}

Since the perception of stress symptoms and of the quality of life did not differ substantially between groups and/or along trimesters, a principal component analysis was carried out to identify interactions among variables that could be masked by simpler statistical approaches. Two components of the database explain twenty three percent of the total variance. The first component (PC1), the psychic/global stress symptoms and the InCaViSa isolation categories, accounts for $12 \%$ of the explained variance (Table 2). The factorial saturation indicated that global stress symptoms obtained the highest score, followed by the InCaViSa isolation category and then by psychic stress symptoms (Table 2).

Table 2. Principal components analysis. In bold values is the difference between the variables with the greatest score contributing to the $A C P$, as well as the value and direction of the correlations.

\begin{tabular}{cll}
\hline Variables & PC1 & PC2 \\
\hline Psychic Stress Symptoms & 0.70 & -0.17 \\
Global Stress Symptoms & 0.75 & -0.19 \\
Isolation & 0.70 & -0.06 \\
Family Problems & 0.27 & -0.70 \\
Responsible Family & 0.12 & -0.79 \\
Happy with the family & 0.07 & -0.80 \\
Spoke of pregnancy & -0.01 & -0.76 \\
Happy Women with pregnancy & 0.15 & -0.75 \\
Happy Family with pregnancy & 0.18 & -0.77 \\
\hline
\end{tabular}

The second principal component ( $\mathrm{PC} 2$; family problems/responsible family/family happiness with pregnancy/open talk with family about pregnancy/happiness with her pregnancy) accounts for the eleven percent of the explained variance (Table 2). In PC2, the category of "happy with 
the family" presented the greatest value, followed by "family responsible", "spoke of the pregnancy", "the family is happy with its child pregnancy" and then "the woman is happy with her pregnancy" (Table 2).

It should be noted that negative values result from negative correlations among the variables, a circumstance that indicates that PC1 variables are the main responsible for the differences found in the sample. However, the contribution that provided the average values of the scores for the ,factor score" of PC1, did not show significant differences between adolescents and non adolescents, nor among trimesters $(\mathrm{F}=0.05, \mathrm{p}<0.95)$; while the PC2 it does $(\mathrm{F}=4.49, \mathrm{p}<0.01 ; \mathrm{F}=9.15, \mathrm{p}<0.005)$.

With respect to differences between trimesters, the third trimester presented the highest average score derived from PC2, which indicates the PC2 increases as pregnancy progresses (Figure 4). Also, the variables of $\mathrm{PC} 2$ affect more the adolescents than non adolescents in the third trimesters (Figure 4).
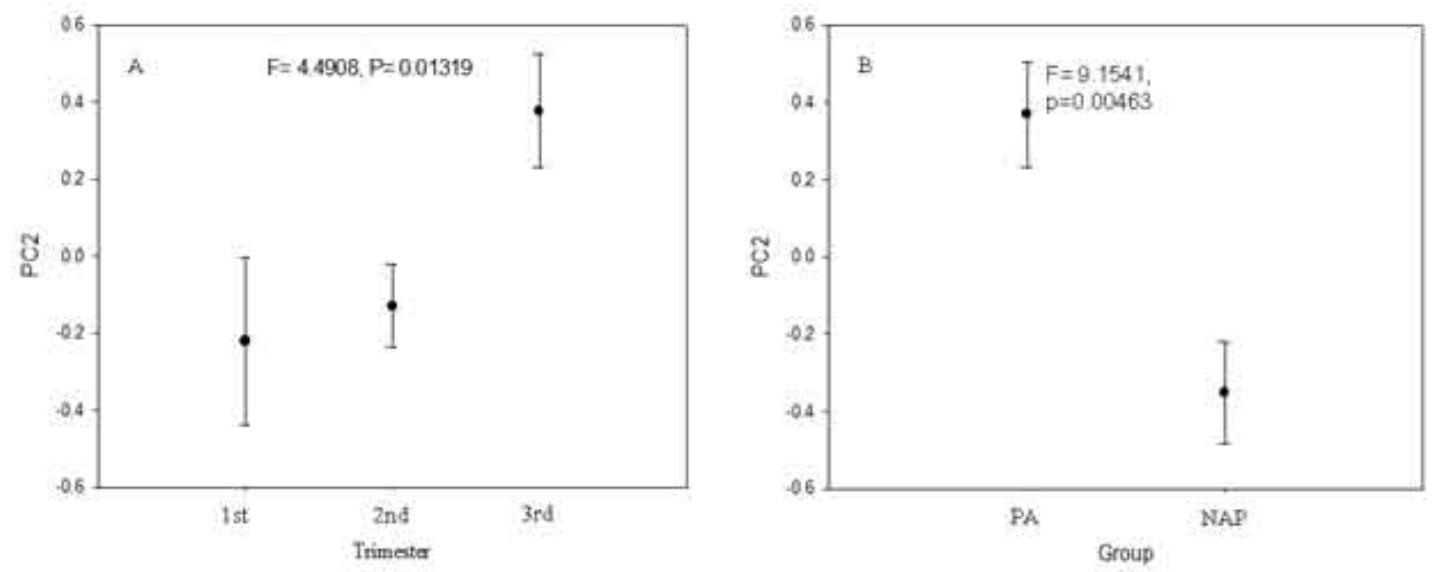

Figure 4. Second Principal Component (PC2) by group and trimester. a) Mean ( \pm CI $95 \%$ ) to the PC2 comparing by trimester. The vertical bars indicate the confidence intervals of $95 \%$. b) Mean ( $\pm \mathrm{CI} 95 \%$ ) to the PC2 comparing by Pregnant adolescent and non adolescent pregnant.

\section{Correlation of Variables}

A Pearson's correlation analysis was performed to evaluate interactions between stress symptoms and the perception of life's quality in both groups of pregnant women (Table 3 ).

Table 2. Variables' correlation according to the participants' condition: Pregnant adolescent (PA), non adolescent pregnant (NAP) and total pregnant women (Total). $* \mathrm{p}<0.05, * * \mathrm{p}<0.001$.

\begin{tabular}{|c|c|c|c|c|c|c|c|c|c|c|c|c|c|c|c|c|}
\hline \multirow[b]{2}{*}{ VARIABLES } & \multicolumn{3}{|c|}{ ISE } & \multicolumn{13}{|c|}{ INCAVISA } \\
\hline & 2 & 3 & 4 & 5 & 6 & 7 & 8 & 9 & 10 & 11 & 12 & 13 & 14 & 15 & 16 & Group \\
\hline \multirow[b]{7}{*}{$\underline{\mathcal{D}}$} & $0.69^{\star *}$ & $0.75^{\star *}$ & $0.94^{* *}$ & $0.26^{*}$ & $-0.42^{* *}$ & $0.42^{* *}$ & $0.65^{\star \star}$ & $0.39^{*}$ & $0.43^{* *}$ & $0.60^{\star *}$ & $0.34^{*}$ & $-0.36^{*}$ & -0.17 & $-0.29^{*}$ & -0.25 & PA \\
\hline & $.75^{\star *}$ & $0.71^{* *}$ & $0.92^{* *}$ & 0.23 & $-0.35^{\star}$ & $0.26^{*}$ & $0.44^{* *}$ & $0.41^{* *}$ & 0.23 & $0.39^{*}$ & $0.48^{* *}$ & -0.06 & -0.17 & -0.07 & -0.14 & NAP \\
\hline & $0.72^{\star *}$ & $0.74^{* *}$ & $0.93^{* *}$ & $0.25^{*}$ & $-0.39^{\star *}$ & $0.36^{* *}$ & $0.56^{* *}$ & $0.41^{\text {** }}$ & $0.36^{* *}$ & ${ }^{*} 0.52^{* *}$ & $0.38^{* *}$ & $-0.22^{*}$ & -0.17 & -0.16 & -0.19 & Total \\
\hline & & $0.61^{* *}$ & $0.83^{* *}$ & $0.26^{*}$ & $-0.41^{*}$ & $0.37^{\star}$ & $0.50^{* *}$ & $0.31^{*}$ & $0.43^{* *}$ & $0.28^{*}$ & $0.36^{*}$ & -0.13 & -0.20 & 0.02 & -0.17 & PA \\
\hline & & $0.72^{* *}$ & $0.89^{* *}$ & 0.12 & $-0.25^{\star}$ & $0.37^{\star}$ & $0.384^{*}$ & $0.50^{\text {** }}$ & 0.18 & $0.35^{*}$ & $0.39^{*}$ & -0.15 & -0.13 & 0.02 & -0.00 & NAP \\
\hline & & $0.66^{* *}$ & $0.86^{* *}$ & $0.20^{*}$ & $-0.33^{* *}$ & $0.37^{\star \star}$ & $0.45^{* *}$ & $0.40^{* *}$ & $0.33^{* *}$ & ${ }^{*} 0.32^{* *}$ & $0.35^{* \star}$ & -0.14 & -0.16 & 0.02 & -0.07 & Total \\
\hline & & & $0.88^{* *}$ & $0.37^{*}$ & -0.20 & $0.58^{* *}$ & $0.71^{\star \star}$ & $0.27^{\star}$ & $0.41^{*}$ & $0.48^{*}$ & $0.28^{*}$ & -0.23 & -0.18 & -0.21 & -0.24 & PA \\
\hline \multirow{3}{*}{$\begin{array}{l}\text { 3. Social } \\
\text { symptoms }\end{array}$} & & & $0.89^{* *}$ & 0.14 & $-0.30^{*}$ & $0.38^{*}$ & $0.40^{*}$ & $0.36^{*}$ & $0.33^{*}$ & $0.32^{*}$ & $0.53^{* *}$ & -0.19 & -0.22 & -0.08 & -0.08 & NAP \\
\hline & & & $0.89^{* *}$ & $0.28^{*}$ & $-0.24^{*}$ & $0.50^{* *}$ & $0.58^{* *}$ & $0.32^{* *}$ & $0.38^{* *}$ & * $0.42^{* *}$ & $0.35^{* *}$ & $-0.21^{*}$ & $-0.20^{*}$ & -0.13 & -0.16 & Total \\
\hline & & & & $0.34^{*}$ & $-0.39^{\star}$ & $0.51^{* *}$ & $0.70^{* \star}$ & $0.38^{*}$ & $0.50^{*}$ & $0.53^{* *}$ & $0.36^{*}$ & $-0.28^{*}$ & -0.20 & -0.21 & $-0.27^{*}$ & PA \\
\hline \multirow{2}{*}{$\begin{array}{l}\text { 4. Global } \\
\text { symptoms }\end{array}$} & & & & 0.19 & $-0.33^{*}$ & $0.37^{*}$ & $0.45^{* *}$ & $0.45^{\star *}$ & $0.29^{*}$ & $0.39^{*}$ & $0.53^{* *}$ & -0.14 & -0.20 & -0.06 & -0.10 & NAP \\
\hline & & & & $0.28^{*}$ & $-0.36^{\star *}$ & $0.45^{\star *}$ & $0.60^{\star *}$ & $0.42^{\star *}$ & $0.42^{* *}$ & * $0.47^{\star *}$ & $0.40^{\star *}$ & $-0.21^{*}$ & $-0.20^{*}$ & -0.12 & $-0.18^{*}$ & Total \\
\hline
\end{tabular}




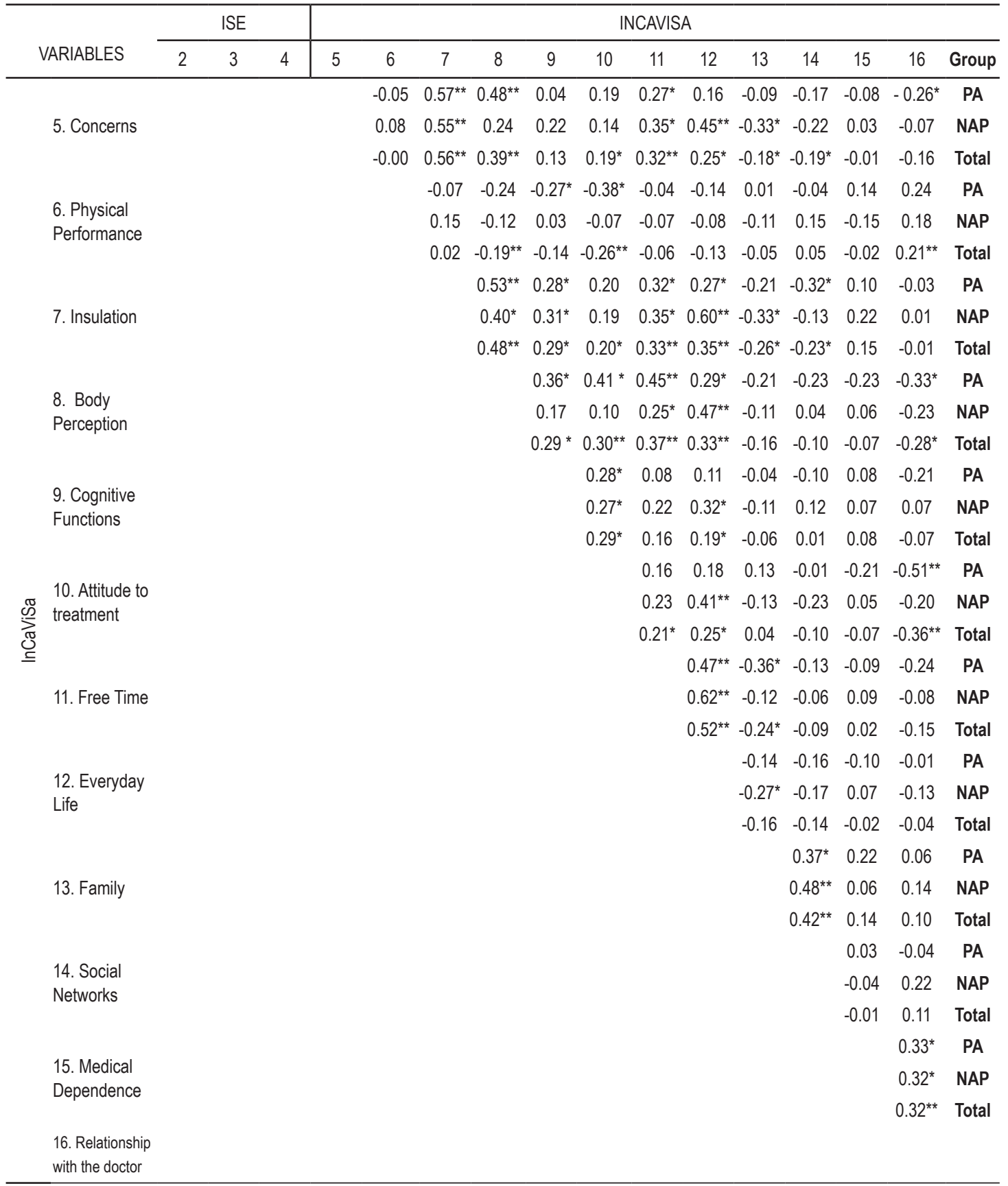

In all pregnant women, it was found that all categories of stress symptoms were positively, significantly correlated. A similar result was obtained for InCaViSa concerns and isolation categories. In addition, "body perception" correlated positively with psychic, social and global stress symptoms. Psychic stress symptoms also were positively correlated with "free time". In spite of the fact that there were other significant correlations, these do not show a strong association (Table 3).

On the other hand, associations among variables differ prominently between groups (Table 3). Indeed, only adolescent pregnant women show positive, significant correlations among: 1) "isolation" and social stress or global stress symptoms, 2) "body perception" and "isolation" or psychic, physical, social and global stress symptoms, 3) global stress symptoms and the attitude to treatment, 4) "free time" and psychic and global stress symptoms (Table 3). In contrast, non adolescents pregnant women show positive significant correlations only among: 1) "everyday life" and social/global stress symptoms, and 2) isolation and free time (Table 3). 
In México, adolescent pregnant women have relatively high morbidity-mortality rates. Unfortunately, the governmental educational campaigns aimed at preventing adolescent pregnancies have failed in reaching their fundamental goal. The detection of factors that predispose adolescent pregnant women to develop fatal conditions is then a priority. In this study we evaluated psychosocial stress, as inferred by assessing the perception of stress symptoms and of the life's quality, as a first step toward the identification of factors that could predispose adolescent pregnant to develop fatal outcomes. Several factors might induce psychosocial stress in adolescent pregnant women. In our cohort, unplanned pregnancies might well be one of them since fifty seven percent of these women reported unwanted pregnancies (for similar results see Arméndariz \& Medel, 2010; León, Minassian, Borgoño \& Bustamante, 2008; ONU, 2007). In support of the above possibility, previous work suggests that psychosocial stress in adolescent women arises from recognizing their selves as being pregnant (Anderson, 2005; Correia, Santos, Calheiros, \& Vieira, 2011; Woods, Melville, Guo, Fan, \& Gavin, 2010). In our case, however, the magnitude of the estimated stress was moderate in pregnant adolescent and non adolescent women. This surprising observation might be explained by the fact that, in contrast to previous studies (León et al., 2008; López, Lugones Botell, Valdespino Pineda, \& Ambrosio San Martín, 2005; Valencia, 2011; Menkes \& Suárez, 2003; Rangel, Valerio, Patiño, \& García, 2004; Rich et al., 2008; Teixeira, Figueiredo, Conde, Pacheco, \& Costa, 2009), in our groups, most pregnant adolescents seem to have adequate emotional support from their couples and their families, even if they are not living with their partners.

Our study show, for the most part, no significant differences in most categories related with the perception of the life's quality between pregnant adolescent and non adolescent women. The exception to this "rule" was observed in the categories of medical dependence and the availability of free time in which adolescent pregnant women obtained lower (especially at the beginning of pregnancy) and higher scores, respectively. Based upon these observations, it appears that the adolescent pregnant women care little about their pregnancy at its initial stages, a circumstance that may explain why these women skip early medical control care, putting in risk the future of their pregnancy, childbirth, and puerperium. In addition, pregnant adolescent women are distress by their lack of free time. The discomfort appears not be high, since stress levels are kept moderate throughout pregnancy in this group of women.

An interesting finding obtained in our study is the fact that life's quality perception was scored normal to high in both groups of pregnant women. This supports that moderate stress symptoms do not cause any deterioration of this parameter in the participants of the present study. This observation is particularly puzzling for adolescent pregnant women since previous studies conducted by Drescher (2003) in the United States and Taşdemir (2010) in Turkey revealed that pregnant adolescent women had lower life's quality perception scores as compared with the general population or with adult pregnant women, respectively. The reasons for this discrepancy are unclear.

In spite of the above discussion, correlation analyses did show associations between stress and the life's quality perception that differ between pregnant adolescents and non adolescent. For example, the high psychic, social and global stress symptoms may lead to bad physical body perception. Similarly, high levels of psychic stress associated with free time restriction decreases the life's quality perception in adolescent pregnant women. In addition, also in this group, the high level of concerns generated an increased perception of social isolation. Hence, only in the case of pregnant adolescents, the presence of any kind of stress causes a bad body perception, a high level of isolation and a perceived worsening of the quality of life (see also Drescher et al., 2003). Nevertheless, the adolescents who present high levels of stress have a better attitude toward the treatment. All of these results can be explained by the fact that at this age adolescents do not have the skills and tools needed to cope with stress because in this period of life the personality is still forming (Diaz Portillo, 1998; Fadiman \& Frager, 2001; Papalia, 2005). 
Alejandro LOYA-JIMENEZ, Godeleva R. ORTIZ-VIVEROS, Armando J. MARTÍNEZ, Gabriel GUTIÉRREZ-OSPINA, Tania ROMO-GONZÁLEZ. Psychosocial Stress and Quality of Life in Pregnant Adolescents

\section{Conclusions}

Adolescent pregnant women suffer of stress moderate levels that may induce a distorted body perception and a relative impoverishment of the perception of the life's quality. These circumstances may lead them to develop a sense of isolation that can be counteracted by the support provided by their couples and families.

\section{References}

Anderson, R. (2005). Stress and pregnancy. The journal of the Royal Society for the Promotion of Health, 125 (5), 215.

Arméndariz, A., \& Medel, B. (2010). Propuesta de intervención para prevenir embarazo en adolescentes. [Proposed intervention to prevent teen pregnancy] SynthesiS, 19-24.

Auchter, M., Galeano, H., \& Zacarías, G. (2004). Maternidad adolescente. Estudio comparativo con madres de más edad. [Teenage motherhood. Comparative study with older mothers]. Universidad Nacional del Noreste, 1, 1-4.

Benavides, A., Moreno, B., Barrosa, E., \& González, J. (2002). La evaluación específica del síndrome de Burnout en psicólogos: el "inventario de Burnout de psicólogos". [Evaluating the Burnout syndrome in psychologists: «The psychologists Burnout inventory»]. Clínica y Salud, 13 (3), 257-283.

Bergman, K., Sarkar, P., O’Connor, T. G., Modi, N., \& Glover, V. (2007). Maternal stress during pregnancy predicts cognitive ability and fearfulness in infancy. Journal of the American Academy of Child and Adolescent Psychiatry, 46 (11), 1454-1463.

Bhattacharya, S., Brewer, S., Davies, J., Meredith, S., \& Preston, P. (2011). El embarazo. [Pregnancy]. Londres: DK.

Correia, D. S., Santos, L. V., Calheiros, A. M., \& Vieira, M. J. (2011). Pregnant teens: signs, symptoms, complications and presence of stress. Revista gaúcha de enfermagem, 32 (1), 40-47.

Diaz, I. (1998). Técnica de la entrevista psicodinámica. [Psychodynamic interview technique]. México: Pax.

Díaz, R., Aguilar, V., \& Santillán, R. (1999). Estrés y embarazo. [Stress and pregnancy]. Revista Asociación Dental Mexicana, 65 (1), 27-31.

Drescher, K., Monga, M., Williams, P., Promecene-Cook, P., \& Schneider, K. (2003). Perceived quality of life in pregnant adolescent girls. American Journal of Obstetrics and Gynecology, 188 (5), 1231-1233.

Fadiman, J., \& Frager, R. (2001). Teorías de la personalidad. [Theories of personality] (2 Ed.). México: Oxford.

Farkas, C., \& Pía, M. (2008). Estudio de las preocupaciones asociadas al embarazo en un grupo de embarazadas primigestas chilenas. [Study of concerns related to pregnancy in a group of first-time Chilean pregnant women]. Revista de Psicología de la Universidad Santo Tomás de Chile, 5(1), 13-20.

Guarino, L., Scremin, F., \& Borrás, S. (2010). Estilo emocional, salud y calidad de vida percibida en embarazadas. [Emotional style, health and perceived quality of life in pregnants]. Revista de Psicología de la Universidad Santo Tomás de Chile, 27 (1), 79-90.

INEGI. (2010). Mujeres y hombres en México 2010. [Women and men in Mexico 2010]. Instituto Nacional de Estadistica y Geografia, 4.

INEGI. (2011). Principales causas de muerte. [Leading causes of death]. Retrieved 05/10/2012, 2012

León, P., Minassian, M., Borgoño, R., \& Bustamante, F. (2008). Embarazo adolescente. [Adolescent pregnancy]. Revista Pedriatría Electrónica, 5 (1), 42-51. 
López, J., Lugones, M., Valdespino, L., \& Ambrosio, S. (2005). Aspectos psicosociales del embarazo en la adolescencia. [Psychosocial aspects of pregnancy in adolescence]. Revista Cubana de Medicina General Integral, 21 (3), 1-8.

Marrero, M., Aguilera, M., \& Aldrete, M. (2008). Estrés psicosocial laboral en embarazadas del sector de la salud de Ciudad de La Habana, Cuba 2005-2006. [Psychosocial stress at work in pregnant health workers from Havana City, Cuba 2005-2006]. Revista Peruana de Medicina Experimental y Salud Pública, $25,200-203$

Menkes, C., \& Suárez, L. (2003). Sexualidad y embarazo adolescente en México. [Sexuality and adolescent pregnancy in Mexico]. Papeles de población 35, 1-31.

Miján de la Torre, A. (2002). Técnicas y métodos de investigación en nutrición humana. [Techniques and methods of research in human nutrition]. Barcelona: Glosa.

Muñoz, M., \& Oliva, P. (2009). Los estresores psicosociales se asocian a sindrome hipertensivo del embarazo $\mathrm{y} / \mathrm{o} \mathrm{sintomas}$ de parto prematuro en el embarazo adolescente. [Psychosocial stressors are associated with pregnancy hypertension and/or symptoms of preterm labor syndrome in teenage pregnancy]. Revista Chilena de Obstetricia y Ginecología, 74 (5), 281-285.

ONU. (2007). Maternidad adolescente en Ámerica Latina y el Caribe. Tendencias, problemas y desafíos. [Teenage motherhood in Latin America and the Caribbean. Trends, problems and challenges]. Desafios, 4, 1-12.

Paarlberg, K., Vingerhoets, A., Passchier, J., Dekker, G., \& Van Geijn, H. (1995). Psychosocial factors and pregnancy outcome: A review with emphasis on methodological issues. Journal of Psychosomatic Research, 39 (5), 563-595.

Papalia, E., Wendkos, S, Duskin, R. (2005). Desarrollo humano (9 Ed.). México: McGraw-Hill.

Rangel, J., Valerio, L., Patiño, J., \& García, M. (2004). Funcionalidad familiar en la adolescente embarazada. [Family functioning in adolescent pregnant]. Revista de la Facultad de Medicina - UNAM, 47 (1), 2427.

Reynolds, R. M., Godfrey, K. M., Barker, M., Osmond, C., \& Phillips, D. I. (2007). Stress responsiveness in adult life: influence of mother's diet in late pregnancy. The Journal of Clinical Endocrinology and Metabolism, 92 (6), 2208-2210. doi: 10.1210/jc.2007-0071.

Rich, J., Mohllajee, A., Kleinman, K., Hacker, M., Majzoub, J., Wright6, R., \& Gillman, M. (2008). Elevated mid-pregnancy corticotropin-releasing hormone is associated with prenatal, but not postpartum, maternal depression. The Journal of Clinical Endocrinology and Metabolism, 10 (1.21).

Riveros, A., Sanchez-Sosa, J., \& Del Águila, M. (2010). Inventario de calidad de vida y salud (InCaViSa). [Quality of life and health Inventory]. México: Manual Moderno.

Ruiz, R., Fullerton, J., \& Dudley, D. (2003). The Interrelationship of Maternal Stress, Endocrine Factors and Inflammation On Gestational Length. Obstetrical \& Gynecological Survey, 58 (6), 415-428.

Senties, M., \& Ortiz, G. (1993). Evaluación de los niveles de ansiedad y el estado emocional en mujeres embarazadas de bajo nivel socioeconómico. [Evaluation of anxiety levels and emotional state in pregnant women of low socioeconomic status]. Licenciatura, Universidad Veracruzana, Xalapa.

SSA. (2002). Prevención del embarazo no planeado en adolescentes. [Preventing unintended pregnancy in adolescents]. Retrieved 2 de enero 2012.

Taşdemir, S., Balci, H., \& Günay, O. (2010). Comparison of life quality of pregnant adolescents with that of pregnant adults in Turkey. Upsala Journal of Medical Sciences, 115 (4), 275-281.

Teixeira, C., Figueiredo, B., Conde, C., Pacheco, A., \& Costa, R. (2009). Anxiety and depression during pregnancy in women and men. Journal of Affective Disorders, 119, 142-148.

Valencia, A. (2011). El embarazo en adolescentes, una fuente importante de estrés. Boletín UNAM-DGCS-272. Retrieved 08/05/2013.

Van der Wal, M., Van Eijsden, M., \& Bonsel, G. (2007). Stress and emotional problems during pregnancy and excessive infant crying. Journal of Developmental and Behavioral Pediatrics, 28 (6), 431-437. 
60
Alejandro LOYA-JIMENEZ, Godeleva R. ORTIZ-VIVEROS, Armando J. MARTÍNEZ, Gabriel GUTIÉRREZ-OSPINA, Tania ROMO-GONZÁLEZ. Psychosocial Stress and Quality of Life in Pregnant Adolescents

Woods, S. M., Melville, J. L., Guo, Y., Fan, M. Y., \& Gavin, A. (2010). Psychosocial stress during pregnancy. American Journal of Obstetrics and Gynecology, 202 (1), 61-67.

Advised by Guna Svence, Riga Teacher Training and Educational Management Academy, Latvia

\begin{aligned} & \hline Alejandro Loya-Jimenez $\begin{array}{l}\text { Master's Student, University of Veracruz, Veracruz, México. } \\ \text { E-mail: psi.cli.alejandro@live.com.mx }\end{array} \\ &$\hline Godeleva R. Ortiz-Viveros $\begin{array}{l}\text { Researcher, University of Veracruz, Veracruz, México. } \\ \text { E-mail: roortiz@uv.mx }\end{array} \\ &$\hline Armando J. Martínez Researcher, University of Veracruz, Veracruz, México. \\ & \hline Gabriel Gutiérrez-Ospina Researcher, National Autonomous University of Mexico, Mexico. \\ & E-mail: gabo@biomedicas.unam.mx \\ & \hline Tania Romo-González PhD., Researcher, University of Veracruz, Veracruz, 2a Schubert No. \\ & (Corresponding author) $\begin{array}{l}\text { Indeco 4 Animas, Xalapa, Ver., Mexico. C. P. 91190, México. } \\ \text { E-mail: tromogonzalez@uv.mx } \\ \text { Website: http://www.uv.mx/personal/tromogonzalez/ }\end{array} \\ &$\hline\end{aligned}

